\title{
Prevalence and diversity of Babesia spp. in questing Ixodes ricinus ticks from Norway
}

\author{
Øivind Øines ${ }^{1 *}$, Jana Radzijevskaja ${ }^{2}$, Algimantas Paulauskas ${ }^{2}$ and Olav Rosef P $^{2,3}$
}

\begin{abstract}
Background: Ixodes ricinus ticks transmit Babesia species to vertebrate hosts. Using molecular tools we were able to detect the presence of this piroplasmid in its vector. The aims of this study were to investigate the prevalence and identity of Babesia species in questing ticks collected in various areas of Norway.

Methods: DNA from questing I. ricinus ticks were examined with a realtime PCR for the presence of Babesia. Positive samples of tick DNA were identified to species using PCR, and sequence analysis.

Results: From a total of 1908 questing I. ricinus ticks, 17 (0.9\%) indicated the presence of Babesia spp. after realtimePCR screening. Ixodes ricinus harbouring Babesia spp. was detected in 9 out of 22 localities. Further molecular analyses of DNA from these positive ticks indicate the presence of Babesia venatorum, $B$. divergens, B. capreoli and a currently undescribed Babesia in Norwegian ticks. The most prevalent was $B$. venatorum found in $71 \%$ of the positive ticks.

Conclusions: A total of 17 out of 1908 (0.9\%) ticks were positive for Babesia. Our data confirm that there are several Babesia species in ticks in Norway. Babesia venatorum was the most prevalent. This species has a zoonotic potential and may cause human babesiosis following a tick bite.
\end{abstract}

Keywords: Babesia spp, Questing Ixodes ricinus, Zoonosis, Piroplasmosis, Realtime PCR, Prevalence, Sequencing

\section{Background}

Ixodes ricinus is ubiquitous in Southern Norway with the highest density near the coast line [1,2]. This tick has the potential to transmit a range of zoonotic pathogens such as tick borne encephalitis virus (TBEV), bacteria causing Lyme disease and granulocytic anaplasmosis, but can also harbor blood parasites such as intraerythrocytic Babesia spp. The parasite can cause malaria-like syndrome in humans and animals as the red blood cell bursts during infections. A fatal Babesia divergens infection in 1956 was the first confirmed case of human babesiosis [3] and ever since, $B$. divergens has been regarded as a causative agent of a potentially life threatening zoonotic infection in humans $[4,5]$.

Babesia divergens may cause disease in healthy and immunocompetent persons [6]. In Europe, $B$. divergens and $B$. venatorum ${ }^{\mathrm{a}}$ are capable of causing severe disease in man, and most often severe cases are described from

\footnotetext{
* Correspondence: oivind.oines@vetinst.no

${ }^{1}$ Norwegian Veterinary Institute, P.O. Box 750, Sentrum 0106, Oslo, Norway Full list of author information is available at the end of the article
}

splenectomised patients [7]. However, in 2004 a fatal babesiosis case was reported in Finland where the diseased person was not splenectomized [8].

In Norway, only one human case of human babesiosis has been described in a splenectomized patient [9], but as this patient had been travelling some time before onset of the disease, it may not be regarded as an autochthonous acquired case. The main pathogen causing human babesiosis in Europe has been regarded as $B$. divergens, however, detailed molecular confirmation has not always been applied to these cases, hence correct diagnosis of the disease causing agent may not always have been carried out. Additionally, the frequent use of serology for diagnosis prevents correct identification to species level.

Babesia also infect and cause disease in other vertebrate hosts. In a study of pastured cows from southern Norway, immunofluorescence (IFAT) revealed that $27 \%$ of the sera investigated showed signs of Babesia antibodies [9]. It has been thought until recently that the only Babesia sp. present in Norway were the causative agent of red water disease in cattle, B. divergens and B. microti found in

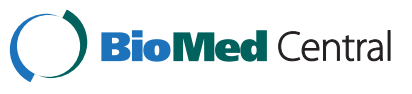


rodents [10]. Recently, an autochthonous canine babesiosis case was reported in a dog from Oslo [11]. Additionally, 4 ticks found on migrating birds in Norway carried B. venatorum [12]. Two ticks came from birds having an eastern migratory route and two came from birds that migrate to Norway via the Atlantic coast of continental Europe [12]. It was hypothesized that these infected ticks were hitchhikers from continental and/or Eastern Europe [12]. In this study we wanted to investigate the prevalence and the species of Babesia in host seeking I. ricinus ticks in various areas of Norway by using molecular tools.

\section{Methods}

\section{Sampling of questing I. ricinus ticks}

Unfed I. ricinus ticks (nymphs and adults) were collected in spring-summer (April to June) seasons during 20062008 from 22 localities (Table 1) spread from southeast to northwest Norway (Figure 1).

The ticks were collected by using a standard flagging method for collecting active ticks on vegetation [13]. The methods involved dragging a $1 \mathrm{~m}^{2}$ piece of white cotton cloth over the vegetation and checking for questing ticks every $10 \mathrm{~m}$. All attached ticks were removed from the cloth and collected into sealed vials containing $70 \%$ ethanol and stored at $4{ }^{\circ} \mathrm{C}$ until analyzed.

\section{DNA extraction}

All ticks were analyzed individually. Extraction of DNA from questing (unfed) ticks was carried out by lysis in ammonium hydroxide $\left(\mathrm{NH}_{4} \mathrm{OH}\right)$, [14,15] with $80 \mu \mathrm{l}$ for nymphs and $100 \mu \mathrm{l}$ for adults. A $2.5 \%$ ammonia solution was used in a $0.5 \mathrm{ml}$ microcentrifuge tube and heated at $99^{\circ} \mathrm{C}$ for $25 \mathrm{~min}$ in a thermostat block (Heating/cooling dry block, BioSan, England). After a brief centrifugation (in order to collect condensate from the cap and sides of the tube) the tubes were opened and heated at $99^{\circ} \mathrm{C}$ for approximately $10-15 \mathrm{~min}$ to evaporate ammonia. The lysates were stored at $4^{\circ} \mathrm{C}$ until use as templates for PCR or at $-20^{\circ} \mathrm{C}$ for longer periods.

\section{Identification of Ixodes ricinus}

The identification of ticks was performed by using appropriate taxonomic keys $[13,16]$ and by molecular assays described in Radzijevskaja et al. [17].

\section{Detection and identification of Babesia spp}

For detection, the primers Bdif (5'-CAG CTT GAC GGT AGG GTA TTG G-3', BdiR (5'-TCG AAC CCT AAT TCC CCG TTA-3') and TaqMan Probe BdiT (5'6-FAM-CGA GGC AGC AAC GG-MGB-3') were used to amplify a $62 \mathrm{bp}$ fragment of the $18 \mathrm{~S}$ rRNA gene of Babesia spp. [18]. Negative and positive controls were included in all runs. A total of 1908 (639 female, 568 male and 701 nymphs) were examined individually.
Table 1 Prevalence of Babesia spp. in host seeking Ixodes ricinus ticks

\begin{tabular}{|c|c|c|c|c|c|c|}
\hline Map ID & Location & Year & No & Nymphs & Female & Male \\
\hline 1 & Mølen** & 2006 & $50(1)$ & 7 & $18(1)$ & 25 \\
\hline 2 & Løvøya** & 2006 & 60 & 14 & 23 & 23 \\
\hline 3 & Hvasser** & 2006 & $23(1)$ & 11 & $8(1)$ & 4 \\
\hline \multirow[t]{3}{*}{4} & Jomfruland & $2006^{* *}$ & 91 & 75 & 8 & 8 \\
\hline & & 2007 & 120 & 60 & 50 & 10 \\
\hline & & 2008 & 94 & 25 & 29 & 40 \\
\hline 5 & Risør & 2006 & $59(1)$ & 22 & 19 & 18(1) \\
\hline \multirow[t]{2}{*}{6} & Tvedestrand & 2006 & $46(1)$ & 19 & 10 & $17(1)$ \\
\hline & & 2007 & $70(1)$ & 5 & 35 & $30(1)$ \\
\hline \multirow[t]{3}{*}{7} & Hinnebu & 2006 & $106(2)$ & $32(2)$ & 42 & 32 \\
\hline & & 2007 & $105(3)$ & $5(1)$ & $48(2)$ & 52 \\
\hline & & 2008 & $58(1)$ & 0 & 32 & $26(1)$ \\
\hline \multirow[t]{2}{*}{8} & Tromøy & 2006 & $41(2)$ & 6 & $24(2)$ & 11 \\
\hline & & 2007 & 37 & 5 & 13 & 19 \\
\hline \multirow[t]{3}{*}{9} & Tjore & 2006 & 24 & 16 & 4 & 4 \\
\hline & & 2007 & 48 & 7 & 19 & 22 \\
\hline & & 2008 & 52 & 14 & 24 & 14 \\
\hline 10 & Odderøya & 2007 & $76(1)$ & 0 & $30(1)$ & 46 \\
\hline 11 & Søgne & 2007 & 25 & 14 & 16 & 5 \\
\hline 12 & Lista & 2007 & 60 & 0 & 28 & 32 \\
\hline 13 & Etne & 2007 & 48 & 48 & 0 & 0 \\
\hline 14 & Mundheim & 2007 & $46(1)$ & $33(1)$ & 8 & 5 \\
\hline 15 & Brekke & 2006 & 9 & 3 & 2 & 4 \\
\hline 16 & Hermansverk & 2007 & 48 & 11 & 33 & 4 \\
\hline 17 & Utvik & 2007 & $48(1)$ & 0 & 22 & $26(1)$ \\
\hline 18 & Hellesylt & 2007 & 9 & 1 & 5 & 3 \\
\hline 19 & Stranda & 2007 & 58 & 29 & 13 & 16 \\
\hline 20 & Surnadal & 2007 & 49 & 0 & 33 & 16 \\
\hline \multirow[t]{3}{*}{21} & Tippheia, Hitra & 2006 & $97(1)$ & $89(1)$ & 5 & 3 \\
\hline & & 2007 & 58 & 0 & 18 & 40 \\
\hline & & 2008 & 46 & 34 & 5 & 7 \\
\hline \multirow[t]{2}{*}{22} & Fjellværsøy, Hitra & 2006 & 64 & 56 & 2 & 6 \\
\hline & & 2007 & 83 & 60 & 23 & 0 \\
\hline \multicolumn{3}{|c|}{ Total in 22 locations } & 1908 & 701 & 639 & 568 \\
\hline \multicolumn{3}{|c|}{ Positive ticks (n)/\% } & (17)/0.9\% & (5)/0.7\% & (7)/1.1\% & (5)/0.9\% \\
\hline
\end{tabular}

*In parenthesis the number of ticks with Babesia spp.

** Radzijevskaja et al. 2008

\section{Sequencing}

Ammonium hydroxide DNA extracts with tick material from samples positive from the realtime PCR screening were purified to maximize DNA yield using Qiagen DNeasy blood and tissue kit (Qiagen, Germany) after overnight lysis in buffer and Proteinase K. The DNA template was then run in a nested PCR using primers 


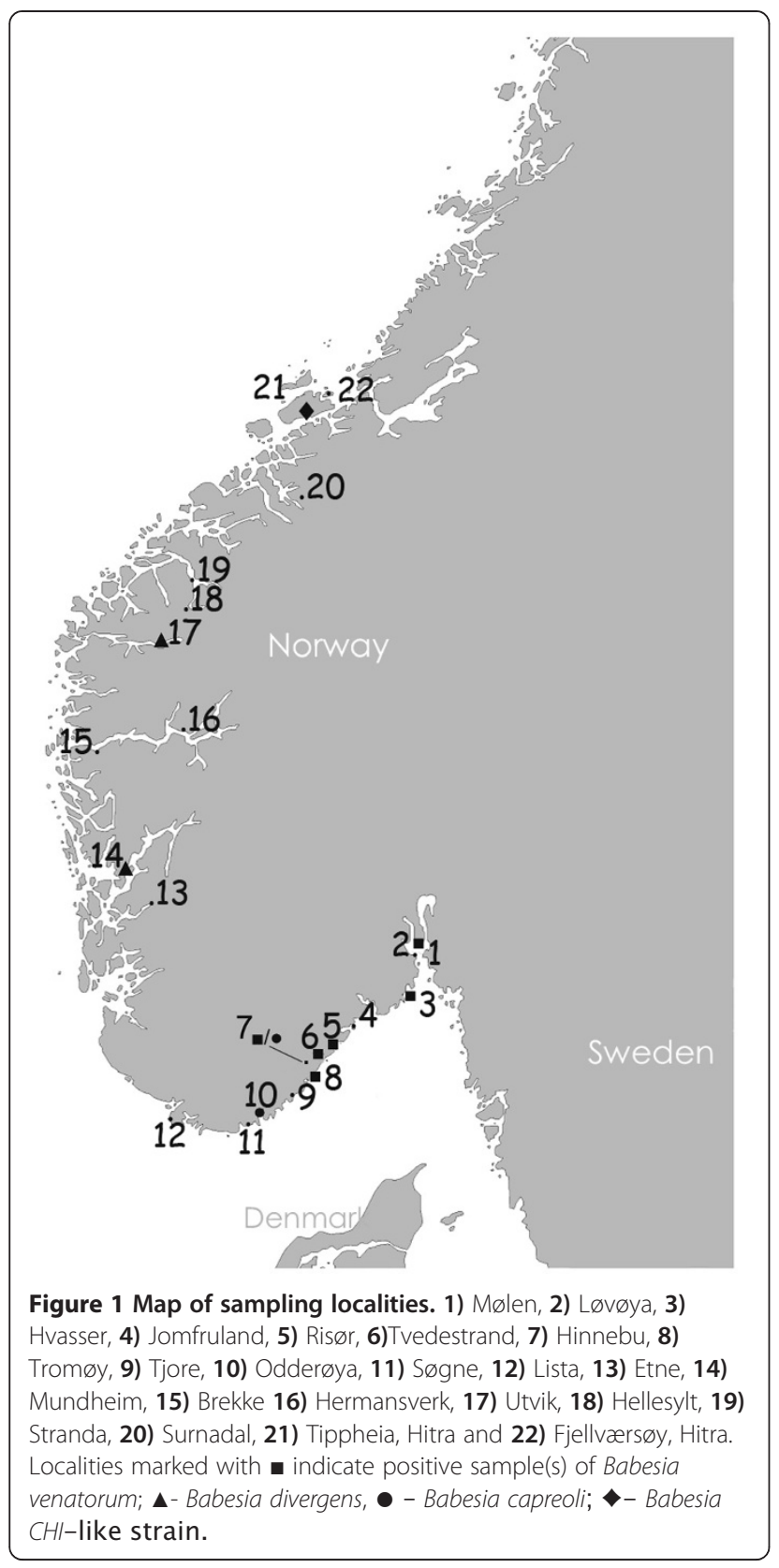

from Protocol II by Zintl et al. [19]. An additional PCR by the same authors (Protocol I) [19] was used for some of the samples after initial analysis of the sequences obtained from Protocol II [19]. One DNA positive control "Mia" from a bovine babesiosis case at Flekke in 2007 (20-30 km N from location 15 'Brekke', Figure 1) was included in the analysis. PCR-products were visualized on a $1.5 \%$ agarose gel using GelRed $^{\mathrm{Tm}}$ DNA-staining reagent (Biotium, Hayward, USA). PCR products were cleaned using Macherel-Nagel Nucleospin Gel and PCRcleanup kit. Products were subsequently sequenced on the AVANT automated sequencer (ABI) using Big Dye sequence mix and the PCR primers for the sequence reaction. Chromatograms from the automated sequencer were imported into Vector NTi Contig Express in Vector Nti Advance ${ }^{\circledR} 11.5$ (Invitrogen, Carlsbad, USA). Chromatograms were manually edited, trimmed prior to assembly. A BLASTn search (http://blast.ncbi.nlm.nih. gov/Blast.cgi) was performed on each of the sequences produced, and top hits were imported and aligned in Align X module of Vector Nti. The alignment of the sequences from the samples and a selected group of top database matches (Figure 2) was exported into MEGA [20] and the nucleotide positions $1076-1549$ relative to a sequence from $B$. divergens (FJ944825), included in the first cluster analysis. Additional analysis of products from Protocol I using positions 481 to 979 of the same Genbank molecule was carried out for the samples unidentifiable from the first analysis.

For tree construction a simple Neighbor-Joining [21] clustering was performed using Jukes-Cantor algorithm [22] and with a bootstrap analysis of 500 replicates. The results from these analyses were used to identify the samples to species level.

\section{Results}

\section{Identification of $I$. ricinus}

Ticks were identified to $I$. ricinus by morphological examination and by successful amplification of a $150 \mathrm{bp}$ product from the 5.8s rRNA pcr [17]. No molecular subtyping was performed on the ticks in this study.

\section{Real-time PCR prevalence}

Babesia spp. positives were found in 17 (0.9\%) out of 1908 I. ricinus ticks, representing 9 out of the 22 sites investigated. The parasite was distributed in adult females with 7 out of $639(1.1 \%)$ in adult males with 5 out of $568(0.9 \%)$ and in nymphs with 5 out of 701 $(0.7 \%)$ respectively. The highest rate was found in ticks from Hvasser with 4.3\% (1 out of 23). Babesia spp. were found every year at Hinnebu with an average of 2.2\% (6 out of 269) (Table 1). The locations where Babesia species were found are indicated in Figure 1.

\section{Nested PCR and sequencing}

A total of 17 ticks yielded sequence products corresponding to Babesia spp. Sequences from twelve of them (71\%) matched sequences of B. venatorum isolates (DP-1562 (JX042314), DP-1563 (JX042315), DP-1564 (JX042316), DP-1565 (JX042317), DP-1567 (JX042318), DP-1568 (JX042319), DP-1569 (JX042320), DP-1570 (JX042321), DP-1571 (JX042322), DP-1572 (JX042323), DP-1574 (JX042325) and DP-1575 (JX042326). Four samples were identical with sequences from the $B$. divergens/ capreoli cluster. These were DP-1573 (JX042324), DP-1576 (JX042327), DP-1577 (JX042328), DP-1578 (JX042329) and 'Mia'. As this $18 \mathrm{~S}$ region in the 3 ' end is 


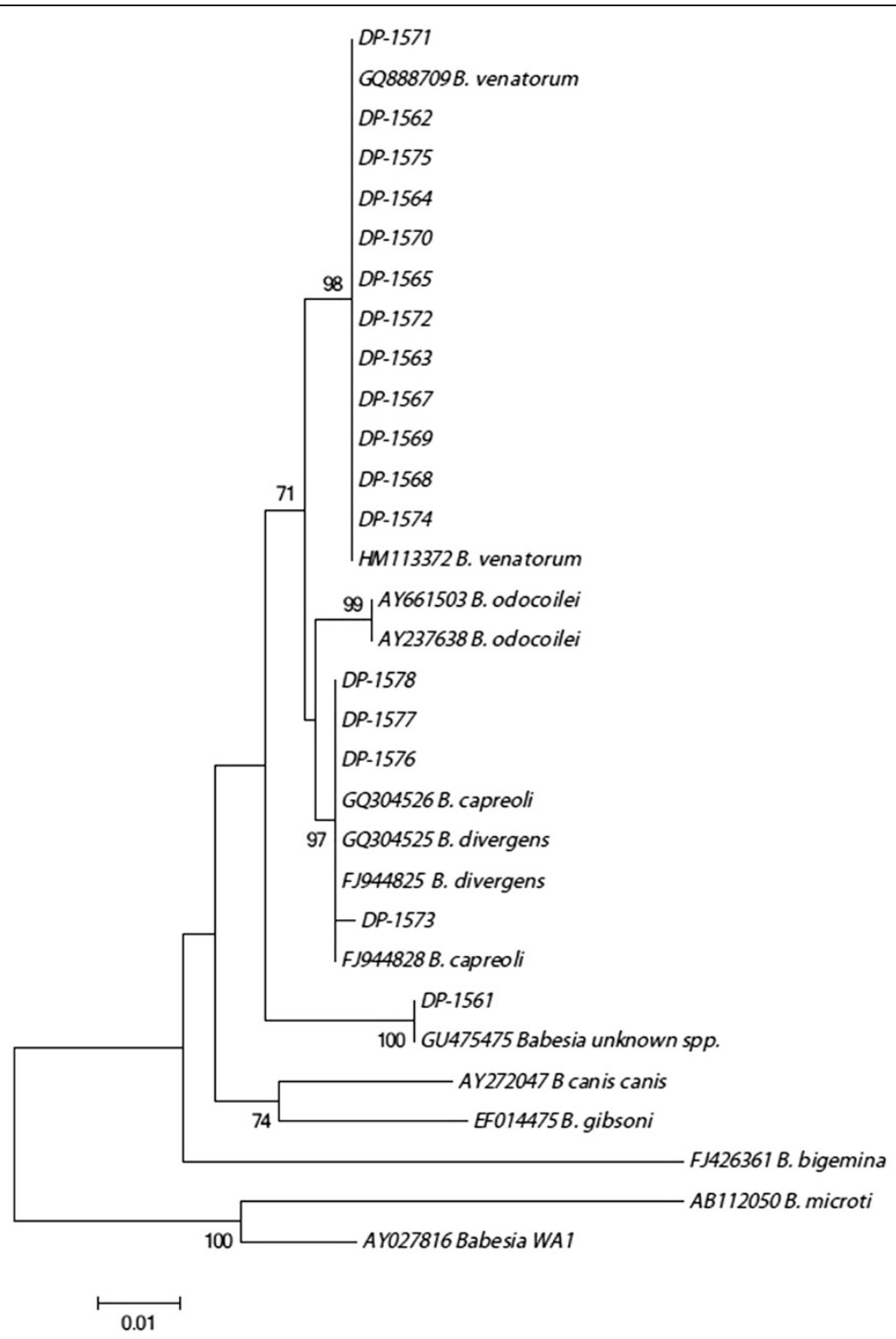

Figure $\mathbf{2}$ The evolutionary relationship inferred using Neighbor-Joining method in $\mathbf{3}$ ' end of $\mathbf{1 8 S}$. Percentages of replicate trees from the bootstrap test (500 replicates) are shown next to branches. The distances were computed using Jukes-Cantor method. The rate variation among sites was modeled with a gamma distribution (shape parameter $=1$ ). The analysis involved a total of 31 nucleotide sequences. All positions containing gaps and missing data were eliminated from analysis. A total of 436 positions were included in the final dataset. These positions corresponded to nucleotides between positions 1076 to 1549 in the B. divergens sequence (FJ944825).

identical for both of these species, an additional PCR was performed which covered a region of $18 \mathrm{~S}$ in which discrimination was possible, described as 'Protocol I' [19]. Sequences obtained by 'Protocol II' [19], revealed that two Babesia DP-1576b (JX083979), DP-1578b (JX083982) (as well as the positive control 'Miab'(JX083981)) were completely identical to B. divergens. DP-1573b (JX083983) and DP1577b (JX083980) were identical to B. capreoli. These identifications were possible due to the nucleotides at positions 634 and 666 related to the Genbank sequence
FJ944825. The remaining sample DP-1561 (JX042313) was significantly different to the various Babesia spp. included into the initial alignment of the $3^{\prime}$ end of 18S. A BLAST search on this variable region alone, revealed a $100 \%$ match with an unknown Babesia (GU475475) described from red deer (Cervus elaphus) in Ireland [19]. The DP-1561 sample was also included in the additional protocol where the 5 'region of the end of the $18 \mathrm{~S}$ was amplified. Analysis of this sequence (Figure 3), DP-1561b (JX083978), revealed similarity to a strain of Babesia from Switzerland (also referred to as 'CH-1') (DQ312432) and 


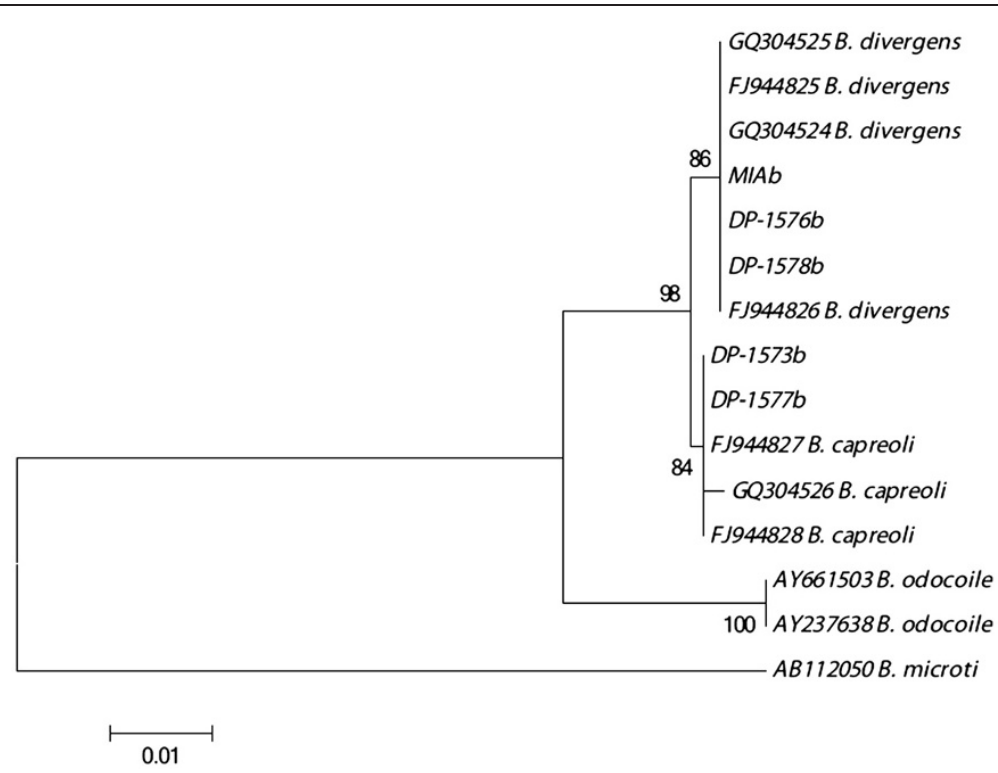

Figure 3 The evolutionary relationship inferred using Neighbor-Joining method using data from $\mathbf{5}^{\prime}$ end of $\mathbf{1 8 S}$. The evolutionary history of a total of 15 sequences was inferred using the Neighbor-Joining method. Next to branches are the percentages of bootstrap replicate trees (500 replicates) in which the samples clustered together are shown next to the branches. The evolutionary distances were computed using JukesCantor and the rate variation among sites was modeled with a gamma distribution. (=1). The analysis included 15 nucleotide sequences. All positions containing gaps and missing data were eliminated. There were a total of 498 positions in the final dataset. Nucleotides used in the calculation corresponded to the nucleotide positions from 481 to 979 , relative to B. divergens sequence (FJ944825).

with a Genbank entry assigned as B. odocoilei-like sequence from Austria (JN543175); but it did not match any of these sequences completely as it differed by two different nucleotides from each of these sequences.

\section{Discussion}

The realtime-PCR analysis of $I$. ricinus revealed an overall Babesia prevalence of $0.9 \%$ in our material. This level is comparable to other studies using similar approaches for detection: in Italy the Babesia sp. 'EU1' prevalence was $0.85 \%$ [23], in Estonia 1,4\% [24], in Poland 1.6\% [25], and corresponds to previous findings in Norway $[12,18]$. In this study we found evidence of the presence of $B$. venatorum, $B$. divergens, $B$. capreoli and one strain of a Babesia very similar to a so far undescribed Babesia in questing I. ricinus.

The most prevalent Babesia in our material was B. venatorum found in $71 \%$ of the positive ticks (Table 2). In Norway, $B$. venatorum has only been reported from ticks on migratory birds [12]. Although B. microti has been previously described from ticks in Norway [10], no ticks with this Babesia were detected in the realtime PCR screening followed by confirmation by PCR and sequence analysis. We used primers designed specifically for $B$. divergens group and in silico analysis of the target region on $18 \mathrm{~S}$ rRNA, reveals that there is only marginal complementarity for the realtime PCR primers and probe used in the initial screening in B. microti rRNA. Taqman probe is only $71 \%$ identical with $B$. microti (AB112050) sequence, whilst forward and rewerse primers are only $77 \%$ and $91 \%$ identical. Thus it is possible that this species and other related Babesia spp. which may vary significantly in this region, may have been missed by our screening analyses. It is also possible that limitations of the use of ammonium hydroxide DNA and incomplete lysis of ticks used in the initial screening may have produced false negative samples. Our prevalence estimate should thereby be an underestimate of the actual Babesia spp. prevalence in ticks in Norway.

The ticks positive for Babesia spp. were recovered from various regions of the country (Figure 1). All ticks infected with $B$. venatorum were found in the southern part of Norway while the $B$. divergens positive ticks were found in the West (Utvik) and South (Odderøya) of Norway. B. capreoli was found in south Norway (Hinnebu). The sample identified as the $\mathrm{CH} 1$-like strain, was recovered at Tippheia at Hitra (Figure 1). This may indicate some difference in the geographic distribution of the Babesia species, with most variants occurring on the South-East coast of Norway. There were a number of sites where we did not find Babesia spp. in this study. However, with a prevalence bordering $1 \%$, and with most sites having sample numbers lower than 100, this may be expected. In Surnadal, however, an outbreak of babesiosis in cattle was recorded the year before our sampling, but no positive samples with Babesia from ticks from this location were recovered in this study. A study from the southern Norwegian coast [9] found that 
Table 2 Babesia species in I. ricinus in different locations, and GenBank nucleotide accession numbers of 18S rRNA gene sequences

\begin{tabular}{|c|c|c|c|c|c|}
\hline Sample ID & host & Location & Genbank ID 5'-end & Genbank ID 3'-end & Identified as \\
\hline DP-1561 & Ixodes ricinus ( $\mathrm{n}$ ) & 21 Tippheia & JX083978 & $J \times 042313$ & Babesia spp. \\
\hline DP-1562 & Ixodes ricinus ( $\mathrm{n}$ ) & 7 Hinnebu & $\mathrm{n} / \mathrm{a}$ & JX042314 & B. venatorum \\
\hline DP-1563 & Ixodes ricinus (n) & 7 Hinnebu & $\mathrm{n} / \mathrm{a}$ & JX042315 & B. venatorum \\
\hline DP-1564 & Ixodes ricinus (f) & 3 Hvasser & $\mathrm{n} / \mathrm{a}$ & JX042316 & B. venatorum \\
\hline DP-1565 & Ixodes ricinus ( $\mathrm{n}$ ) & 1 Mølen & $\mathrm{n} / \mathrm{a}$ & JX042317 & B. venatorum \\
\hline DP-1567 & Ixodes ricinus (f) & 8 Tromøy & $\mathrm{n} / \mathrm{a}$ & JX042318 & B. venatorum \\
\hline DP-1568 & Ixodes ricinus (f) & 5 Risør & $\mathrm{n} / \mathrm{a}$ & JX042319 & B. venatorum \\
\hline DP-1569 & Ixodes ricinus (f) & 8 Tromøy & $\mathrm{n} / \mathrm{a}$ & JX042320 & B. venatorum \\
\hline DP-1570 & Ixodes ricinus (m) & 6 Tvedestrand & $\mathrm{n} / \mathrm{a}$ & JX042321 & B. venatorum \\
\hline DP-1571 & Ixodes ricinus (m) & 6 Tvedestrand & $\mathrm{n} / \mathrm{a}$ & JX042322 & B. venatorum \\
\hline DP-1572 & Ixodes ricinus ( $\mathrm{n}$ ) & 7 Hinnebu & $\mathrm{n} / \mathrm{a}$ & JX042323 & B. venatorum \\
\hline DP-1573 & Ixodes ricinus (f) & 7 Hinnebu & JX083983 & JX042324 & B. capreoli \\
\hline DP-1574 & Ixodes ricinus (f) & 7 Hinnebu & $\mathrm{n} / \mathrm{a}$ & JX042325 & B. venatorum \\
\hline DP-1575 & Ixodes ricinus (m) & 7 Hinnebu & $\mathrm{n} / \mathrm{a}$ & JX042326 & B. venatorum \\
\hline DP-1576 & Ixodes ricinus ( $\mathrm{n}$ ) & 14 Mundheim & JX083979 & JX042327 & B. divergens \\
\hline DP-1577 & Ixodes ricinus (f) & 10 Odderøya & JX083980 & JX042328 & B. capreoli \\
\hline DP-1578 & Ixodes ricinus (m) & 17 Utvik & JX083982 & JX042329 & B. divergens \\
\hline Mia & Bovine babesiosis & Flekke* & JX083981 & $\mathrm{n} / \mathrm{a}$ & B. divergens \\
\hline
\end{tabular}

$\mathrm{n}$ - nymph, $\mathrm{f}$ - female, $\mathrm{m}$ - male;

$\mathrm{n} / \mathrm{a}$ - sequencing were not performed

* -Positive control came from a clinical ill cow sampled from 'Flekke' location situated approximately 25 km N of location 15 , 'Brekke' in Figure 1.

17 of 25 cows from Jomfruland were seropositive for Babesia. However, no Babesia positive ticks were found in Jomfruland in Radzijevskaja et al. [18], and this study, when a total of 305 ticks were investigated. More investigations should elaborate on this.

The ticks investigated in this study were questing ticks sampled in the vegetation in spring and early summer. Babesia venatorum was encountered more frequently in this study than expected, indicating that there is a widespread distribution of this Babesia species on the SouthEast coast of Norway. Babesia venatorum is naturally transmitted by I. ricinus [26], and roe deer has been regarded as the main cervid hosts. We do know that the areas sampled on the South East coast of Norway generally has a high roe deer population. The wild cervids are thought to be the main hosts for I. ricinus in the areas sampled. As roe deer is regarded as the main vertebrate host for B. venatorum it is therefore likely that this Babesia can be regarded endemic to Norway. More studies of the vertebrate host population should be carried out to prove this. Detection of host DNA in fed ticks, or additional sampling of wild cervids to identify vertebrate reservoirs in the areas may provide valuable information. Regardless of the infection routes, if $B$. venatorum has similar properties as $B$. divergens which include transovarial and transstadial transmission [27], and may last for two tick generations [28], the infected tick populations may on their own be regarded as reservoirs for Babesia [9]. The recording of B. venatorum will be of public health importance as these ticks can act as vectors of the pathogen to man in periods of the year filled with outdoor activities. One of the sites of our sampling (Tromøy) is a popular arena for annual festivals with lot of human activity.

This study reports $B$. venatorum, $B$. divergens, $B$. capreoli and the so far undescribed species, Babesia $\mathrm{CH} 1$-like strain to be present in ticks in Norway. Babesia ventorum from ticks on birds and $B$. divergens as a pathogen on cattle has been reported before [12], but this is the first detection of $B$. capreoli in Norway. The vertebrate host of $B$. capreoli is roe deer, and it is closely related to $B$. divergens but is regarded as a separate species [29]. Babesia capreoli does not pose a threat to humans or livestock as experiments show that it is not capable of multiplying in blood from humans or cows [29].

In this study we also recovered a special Babesia variant from the island of Hitra (DP-1561).

This Babesia strain was identical to a red deer $(C$. elaphus) Babesia variant found in Ireland [19] when compared to the sequence from the $3^{\prime}$ end of the region of $18 \mathrm{~S}$ 
(Figure 2). Zintl and colleagues [19] described the unknown variant they identified using the 3 ' end of $18 \mathrm{~S}$ from red deer. Unfortunately, no sequence information was available for Zintl's irish isolates at the $5^{\prime}$ end of $18 \mathrm{~S}$ at the time of analysis. We amplified the $5^{\prime}$ end of DP-1561 and a separate blast search of this sequence revealed that this variant clustered with Babesia sp. genotype CH1'(DQ312432) sampled from red deer in Switzerland [30]. It also clustered with a Genbank sequence from Austria (JN543175), although not part of a published work yet, it was described as a B. cf. odocoilei from red deer. (DP-1561b differed by only 2 nucleotides with respect to sequence DQ312432 and JN543175. One of the nucleotides in which variation was seen in our sample included a polymorphic site in our sample, representing a $\mathrm{G}$ or $\mathrm{T}$, either nucleotides not seen in the Genbank sequences. The remaining altered nucleotide was due to a nucleotide only seen in $\mathrm{CH} 1$ (a $\mathrm{T}$ nucleotide at position 333), or a nucleotide seen only in B. cf. odocoilei (a G nucleotide at position 145). The Babesia detected in DP-1561 appears to represent a new variant, which seems to be an intermediate version of these two 'unknown' genbank entries. This unknown Babesia is identical in the 3' sequence of $18 \mathrm{~S}$ to the strain that Zintl and colleagues [19] found in Ireland and very similar to what researchers discovered in Switzerland and Austria when comparing the $5^{\prime}$ ' end of the molecule, hence it should be regarded "CH1-like". Regardless of its species status Zintl et al. [19], Hilpertshauser [30] and the authors of the Genbank entry JN543175 found this variant in red deer. We found this isolate in the West coast of Norway 'Hitra', and this island has a very high density of red deer (C. elaphus) and roe deer (Capreolus capreolus) [31]. Most likely it is the red deer population in Hitra that harbors this Babesia recovered in sample DP-1561.

Although screening of wild cervids in Norway may contribute to the knowledge of possible wild reservoirs of these Babesia species, it seems from our identified strains that roe deer and red deer may be the most important hosts for the Babesia we have found in this study. The possible role of moose and reindeer as reservoirs for Babesia in Norway remains unknown. Recently, there have been reports of reindeer fatalities due to Babesia [32], and severe infections of reindeer due to $B$. divergens and B. odocoilei $[33,34]$, suggesting that reindeer may not be a good reservoir host as these pathogens may give rise to severe disease when encountered. Given that the I. ricinus ticks carrying Babesia would encounter reindeer babesiosis in reindeer in Norway may be possible. However, as the habitats of roe deer and reindeer rarely overlap and the tick density is relatively low in the mountain habitats of reindeer, this may generally not be the case.

Babesiosis in man and animals normally only occur transiently and symptoms normally are general and mild.
It is therefore possible that the disease may be underdiagnosed in Norway. Problems related to the difficulty of diagnosis and the lack of screening laboratories [6], may contribute to a possible under-diagnosis of human babesiosis in Norway.

\section{Conclusions}

This study employed molecular tools for the presence of Babesia spp. in questing I. ricinus ticks sampled in various regions of Norway. Four species of Babesia were encountered suggesting that Babesia is distributed in the tick population throughout Southern Norway. Babesia venatorum dominated, being identified in 12 out of 17 isolates. Babesia divergens, B. capreoli and a currently undescribed Babesia was detected.

\section{Endnotes}

a The current status of the name Babesia venatorum as a formal taxononomic name remains debatable, as full formal species description is not available. These strains have originally been referred to as Babesia sp. 'EU1' [5]. For simplicity we refer to it as Babesia venatorum in the current report.

\section{Competing interest}

The authors declare that they have no competing interest.

\section{Authors' contributions}

$\varnothing \varnothing$ performed the PCR, sequencing and molecular analysis of positive ticks from realtime PCR as well as interpretation of the molecular data and preparation of the manuscript.

JR performed the realtime PCR, calculated the prevalence and together with AP collected ticks, and contributed with revision of the manuscript. OR

designed the study, contributed with collection of ticks and contributed to the preparation of the manuscript.

All authors read and approved the final manuscript.

\section{Author details}

${ }^{1}$ Norwegian Veterinary Institute, P.O. Box 750, Sentrum 0106, Oslo, Norway.

2Department of Biology, Vytautas Magnus University, Vileikos str. 8, Kaunas

LT-44404, Lithuania. ${ }^{3}$ ATP-Innovation AS, 3800, Bø i Telemark, Norway.

Received: 20 June 2012 Accepted: 25 July 2012

Published: 4 August 2012

\section{References}

1. Mehl R: The distribution and host relations of Norwegian ticks (Acari, Ixodides). Fauna Norvegica 1983, 30:46-50.

2. Jore $S$, Viljugrein $H$, Hofshagen $M$, Brun-Hansen $H$, Kristoffersen $A B$, Nygård K, Brun E, Ottesen P, Sævik BK, Ytrehus B: Multi-source analysis reveals latitudinal and altitudinal shifts in range of Ixodes ricinus at its northern distribution limit. Parasit Vectors 2011, 4:84-95.

3. Skrabalo Z, Deanovic Z: Piroplasmosis in man; report of a case. Doc Med Geogr Trop 1957, 9:11-16.

4. Homer MJ, Anguilar-Delfin I, Telford SR, Krause PJ, Persing DH: Babesiosis. Clin Microbiol Rev 2000, 13:451-469.

5. Herwaldt BL, Caccio S, Gherlinzoni F, Aspock H, Slemenda SB, Piccaluga P, Martinelli G, Edelhofer R, Hollenstein U, Poletti G, Pampiglione S, Loschenberger K, Tura S, Pieniazek NJ: Molecular characterization of a non-Babesia divergens organism causing zoonotic babesiosis in Europe. Emerg Infect Dis 2003, 9:942-948.

6. Martinot M, Zadeh MM, Hansmann Y, Grawey I, Christmann D, Aguillon S, Jouglin M, Chauvin A, De Briel D: Babesiosis in immunocompetent patients, Europe. Emerg Infect Dis 2011, 17:114-116. 
7. Zintl A, Mulcahy G, Skerrett HE, Taylor SM, Gray JS: Babesia divergens a bovine blood parasite of veterinary and zoonotic importance. Clin Rev Microbiol 2003, 16:622-636.

8. Haapasalo K, Soumalainen P, Sukura A, Siikamaki H, Jokiranta TS: Fatal babesiosis in man, Finland, 2004. Emerg Infec Dis 2010, 16:1116-1118.

9. Hasle G, Bjune GA, Christensson D, Røed KH, Whist AC, Leinaas HP: Detection of Babesia divergens in sothern Norway by using an immunofluorescence antibody test in cow sera. Acta Vet Scand 2010 52:55.

10. Wiger R: Seasonal and annual variations in the prevalence of blood parasites in cyclic species of small rodents in Norway with special reference to Clethrionomys glareolus. Holarctic Ecol 1979, 2:169-175.

11. Øines $\varnothing$, Storli $K$, Brun-Hansen $H$ : First case of babesiosis caused by Babesia canis canis in a dog from Norway. Vet Parasitol 2010, 171:350-353.

12. Hasle G, Leinaas HP, Røed KH, Øines Ø: Transport of Babesia venatoruminfected Ixodes ricinus to Norway by northward migrating passerine birds. Acta Vet Scand 2011, 53:41.

13. Hillyard R: Ticks of North-West Europe. In Synopsis of the British Fauna (New Series). Edited by Barnes RSK, Crothers JH. London: The Natural History Museum; 1996:178. 58.

14. Rijpkema S, Golubic D, Molkenboer M, Verbeek-De Kruif N, Schellekens J: Identification of four genomic groups of B. burgdorferi sensu lato in $I$. ricinus ticks collected in a Lyme borreliosis endemic region of Northern Croatia. Exp Appl Acarol 1996, 20:23-30.

15. Stañczak J, Racewicz B, Kubica-Biernat W, Kruminis-Lozowska J, Dabrowski A, Markowska M: Prevalence of Borrelia burgdorferi sensu lato in Ixodes ricinus ticks (Acari, Ixodidae) in different Polish woodlands. Ann Agric Environ Med 1999, 6:127-132

16. Filippova NA: Ixodid ticks of the subfamiliy Ixodinae. Fauna in the USSR. Arachnidea, Vol 4. Leningrad: Nauka; 1977.

17. Radzijevskaja J, Indriulytë R, Paulauskas A, Ambrasienë D, Turčinavičienë J: Genetic polymorphism study in Ixodes ricinus $L$ ticks population of Lithuania using RAPD markers. Acta Zool Lith 2005, 15:341-348.

18. Radzijevskaja J, Paulauskas A, Rosef O: Prevalence of Anaplasma phagocytophilum and Babesia divergens in Ixodes ricinus ticks from Lithuania and Norway. Int J Med Microbiol 2008, 298S1:218-221.

19. Zintl A, Finnerty EJ, Murphy TM, Waal TM, Gray J: Babesias of red deer (Cervus elaphus) in Ireland. Vet Res 2011, 42:7.

20. Tamura K, Peterson D, Peterson N, Stecher G, Nei M, Kumar S: MEGA5: Molecular evolutionary genetics analysis using maximum likelihood, evolutionary distance, and maximum parsimony methods. Mol Biol Evol 2011, 28:2731-2739. http://www.megasoftware.net.

21. Saitou N, Nei M: The neighbor-joining method: A new method for reconstructing phylogenetic trees. Mol Biol Evol 1987, 4:406-425.

22. Jukes TH, Cantor CR: Evolution of protein molecules. In Mammalian Protein Metabolism. Edited by Munro HN. New York: Academic Press; 1969:21-132.

23. Cassini R, Bonoli C, Montarsi F, Tessarin C, Marcer F, Galuppi R: Detection of Babesia EU1 in Ixodes ricinus ticks in northern Italy. Vet Parasitol 2010, 171:151-154.

24. Katargina $O$, Geller J, Vasilenko V, Kuznetsova $T$, Järvekűlg $L$, Vene $S$, Lundkvist $\AA$, Golovljova I: Detection and characterization of Babesia species in Ixodes ticks in Estonia. Vector Borne Zoonotic Dis 2011, 11:923-928

25. Cieniuch S, Stańczak J, Ruczaj A: The first detection of Babesia EU1 and Babesia canis canis in Ixodes ricinus ticks (Acari, Ixodidae) collected in urban and rural areas in northern Poland. Polish J Microbiol 2009, 58:231-236

26. Becker CA, Bouju-Albert A, Jouglin M, Chauvin A, Malandrin L: Natural transmission of zoonotic Babesia spp. by Ixodes ricinus ticks. Emerg Infect Dis 2009, 15:320-322.

27. Bonnet S, Jouglin M, Malandrin L, Becker C, Agoulon A, L'Hostis M, Chauvin A: Transstadial and transovarial persistence of Babesia divergens DNA in Ixodes ricinus ticks fed on infected blood in a new skin-feeding technique. Parasitology 2007, 134:197-207.

28. Donnelly J, Peirce MA: Experiments on the transmission of Babesia divergens to cattle by the tick Ixodes ricinus. Int J Parasitol 1975, 5:363-367.

29. Malandrin L, Joughlin M, Sun Y, Brisseau N, Chauvin A: Redescription of Babesia capreoli (Enigk and Friedhoff, 1962) from roe deer (Capreolus capreolus): Isolation, cultivation, host specificity, molecular characterisation and differentiation from Babesia divergens. Int J Parasitol 2010, 40:277-284.
30. Hilpertshauser H, Deplazes P, Schnyder M, Gern L, Mathis A: Babesia spp. Identified by PCR in ticks collected from domestic and wild ruminants in Southern Switzerland. Appl Environ Microbiol 2006, 72:6503-6507.

31. Rosef O, Paulauskas A, Radzijevskaja J: Prevalence of Borrelia burgdorferi sensu lato and Anaplasma phagocytophilum in questing Ixodes ricinus in relation to the density of wild cervids. Acta Veterinaria Scandinavia 2009, 51(47):1-8.

32. Kik M, Nijhof AM, Balk JA, Jongejan F: Babesia sp. EU1 infection in a forest reindeer, the Netherlands. Emerg Infect Dis 2011, 17(5):936-938.

33. Langton C, Gray JS, Waters PF, Holman PJ: Naturally acquired babesiosis in a reindeer (Rangifer tarandus tarandus) herd in Great Britain. Parasitol Res 2003, 89:194-198.

34. Bartlett SL, Abou-Madi N, Messick JB, Birkenheuer A, Kollias GV: Diagnosis and treatement of Babesia odocoilei in captive reindeer (Rangifer tarandus tarandus) and recognition of three novel host species. J Zoo Wildl Med 2009, 440:152-159.

\section{doi:10.1186/1756-3305-5-156}

Cite this article as: Øines et al:: Prevalence and diversity of Babesia spp. in questing Ixodes ricinus ticks from Norway. Parasites \& Vectors 2012 5:156.

\section{Submit your next manuscript to BioMed Central and take full advantage of:}

- Convenient online submission

- Thorough peer review

- No space constraints or color figure charges

- Immediate publication on acceptance

- Inclusion in PubMed, CAS, Scopus and Google Scholar

- Research which is freely available for redistribution

Submit your manuscript at www.biomedcentral.com/submit
C BioMed Central 